$\sqrt{73}-12808$

NASA TECHNICAL NOTE

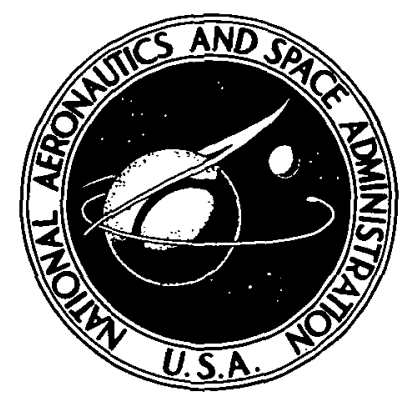

NASA TN D-71TO

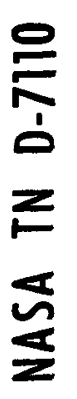

MINIMIZING THE AREA REQUIRED

FOR TIME CONSTANTS

IN INTEGRATED CIRCUITS

by John C. Lyons

Goddard Space Flight Center

Greenbelt, Md. 20771

NATIONAL AERONAUTICS AND SPACE ADMINISTRATION - WASHINGTON, D. C. - NOVEMBER-1972 


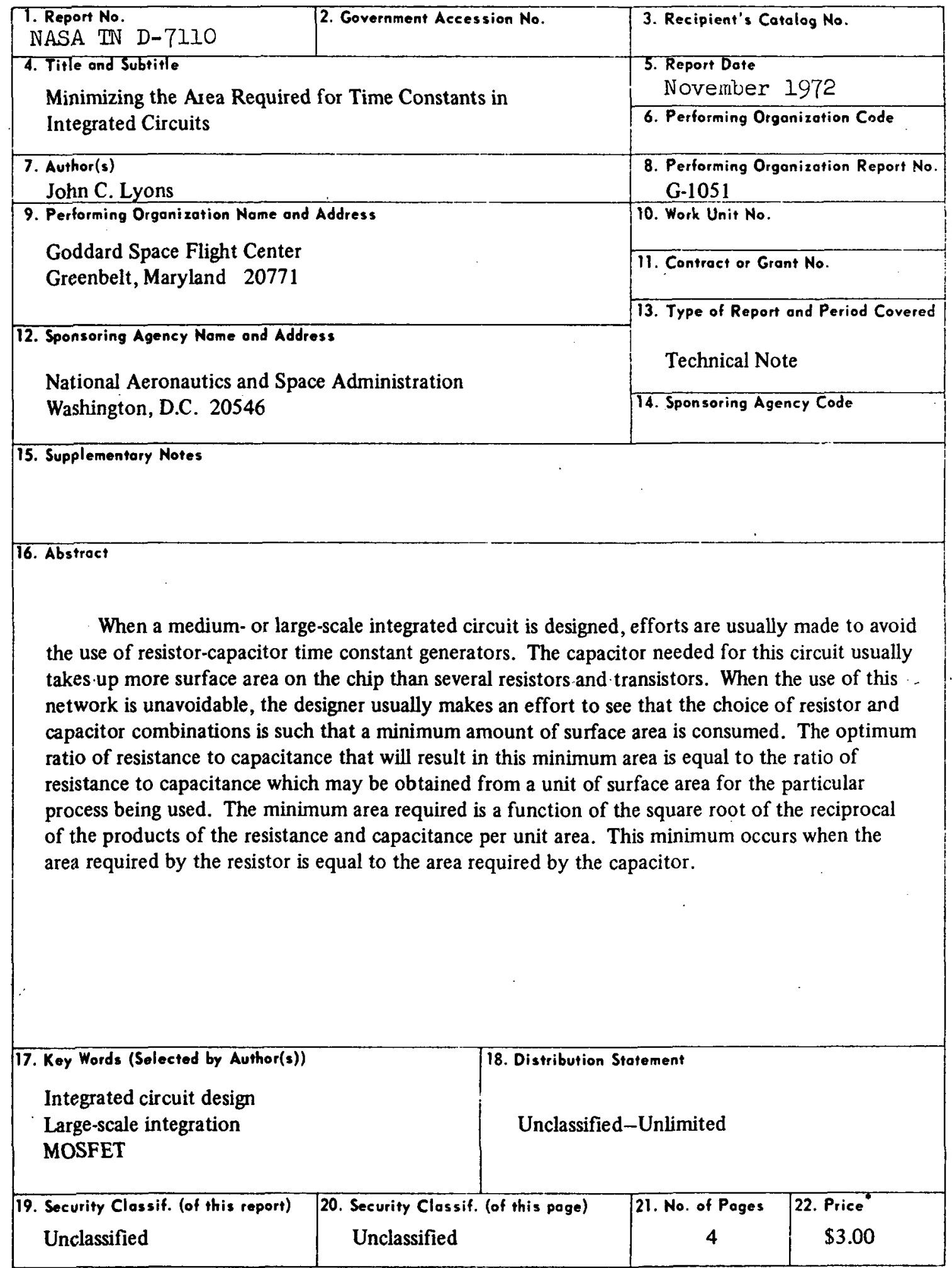

- For sale by the National Technical Information Service, Springfield, Virginia 22151. 


\title{
MINIMIZING THE AREA REQUIRED FOR TIME CONSTANTS IN INTEGRATED CIRCUITS
}

\author{
John C. Lyons \\ Goddard Space Flight Center
}

One of the most widely used networks in pulse and digital circuitry is the simple resistor-capacitor time constant generator. There are an infinite number of combinations of resistor and capacitor values that will provide the required time constant. When circuits are designed that use conventional, discrete components, the selection of these constants is determined by such factors as impedance matching, power dissipation, and the range of component values readily available. Most aerospace applications place a premium on small size and light weight. For this reason, the range of capacitance values used is usually restricted to those that are available in relatively small case sizes.

When designing a resistor-capacitor time constant for an integrated circuit, the designer must take into consideration the fact that the surface area needed for the components is of equal importance to power dissipation and impedance matching. The particular semiconductor fabrication process being used usually determines the amount of resistance or capacitance to be built into a unit area of integrated circuit surface. A capacitor value may be doubled by simply doubling the surface area of the component on the integrated circuit chip. In the case of a resistor, the resistance may be doubled by adding unit areas in series or may be halved by adding them in parallel. (See fig. 1.) For this reason, the standard terminology for resistivity of a resistor is ohms per square. The side dimension of the square is not important in that doubling or halving the length of the resistor accomplishes a corresponding dimensional change in the width, and the resistance remains constant.

The calculations in this document concern cases in which the value of the resistor increases rather than decreases as its area increases. The relationships between the required time constant $t$, the
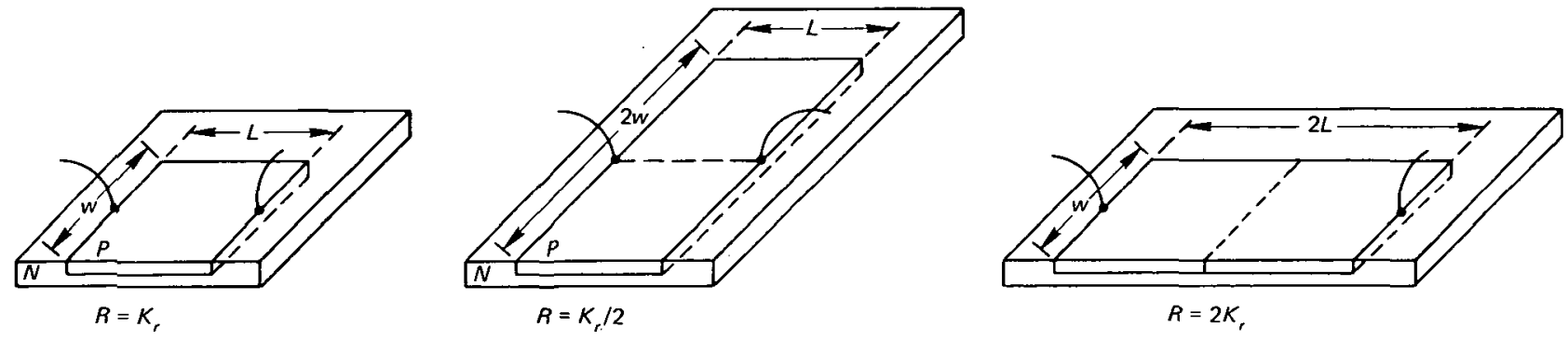

Figure 1.-Methods of changing the value of the resistance. 
resistance $R$, the capacitance $C$, and the areas of the resistance $A_{r}$ and capacitance $A_{c}$ components and their total $A_{t}$ are shown in the following equations:

$$
\begin{array}{rl}
t & =R C \\
A_{t} & =A_{c}+A_{r} \\
\vdots & =\frac{C}{K_{c}} \\
A_{c} & R \\
A_{r} & =\frac{R}{K_{r}} .
\end{array}
$$

where $K_{c}$ and $K_{r}$ are sheet capacitance and sheet resistivity, respectively.

Substituting equations (3) and (4) into equation (2) yields

$$
A_{t}=\frac{C}{K_{c}}+\frac{R}{K_{r}}
$$

and substituting $C=t / R$ from equation (1) into equation (5) yields

$$
A_{t}=\frac{t}{R K_{c}}+\frac{R}{K_{r}}
$$

This equation shows that the value of $A_{t}$ required for $t$ can be described as a function of $t, R, K_{r}$, and $K_{c}$. If $t, K_{c}$, and $K_{r}$ are held constant, $A_{t}$ and $R$ are variables. Next, $A_{t}$ is differentiated with respect to $R$ :

$$
\frac{d A_{t}}{d R}=\frac{-t}{R_{m}^{2} K_{c}}+\frac{1}{K_{r}}
$$

(Throughout this document, subscript $m$ is used to indicate minimum.) The resulting cifferential is set equal to zero to find $R_{m}$ :

Therefore,

$$
\frac{-t}{R_{m}^{2} K_{c}}+\frac{1}{K_{r}}=0
$$

$$
R_{m}=\sqrt{\frac{t K_{r}}{K_{c}}}
$$

Substituting $R=t / C$ from equation (1) into equation (5) and using the same method yields 


$$
C_{m}=\sqrt{\frac{t K_{c}}{K_{r}}}
$$

The total minimum area required is the sum of the areas of each of the two minimum components:

From equation (5),

$$
A_{t_{m}}=A_{r_{m}}+A_{c_{m}}
$$

$$
A_{t_{m}}=\frac{C_{m}}{K_{c}}+\frac{R_{m}}{K_{r}}
$$

Substituting equations (9) and (10) into equation (12) yields

$$
\begin{aligned}
A_{t_{m}} & =\sqrt{\frac{t}{K_{c} K_{r}}}+\sqrt{\frac{t}{K_{c} K_{r}}} \\
& =\sqrt{\frac{4 t}{K_{c} K_{r}}}
\end{aligned}
$$

This equation describes the minimum area required for a time constant when $t, K_{c}$, and $K_{r}$ are known. It is interesting to note that $A_{t_{m}}$ occurs when $A_{c}$ is equal to $A_{r}$.

From equations (9) and (10),

$$
\begin{aligned}
\frac{R_{m}}{C_{m}} & =\frac{\sqrt{t K_{r} / K_{c}}}{\sqrt{t K_{c} / K_{r}}} \\
& =\frac{K_{r}}{K_{c}}
\end{aligned}
$$

Thus, the ratio of $R_{m}$ to $C_{m}$ that yields the minimum area required is shown in equation (14) to be the ratio of $K_{r}$ to $K_{c}$.

A typical application of this relationship would be that of a metal-oxide-silicon field-effect transistor (MOSFET) integrated circuit. $K_{r}$ provided by this process is $39 \mathrm{~T} \Omega / \mathrm{m}^{2}\left(25 \mathrm{G} \Omega / \mathrm{in}^{2}\right)$, and $K_{c}$ is $390 \mu \mathrm{F} / \mathrm{m}^{2}\left(250 \mathrm{nF} / \mathrm{in}^{2}\right)$. Values for $A_{r}, A_{c}, A_{t}$, and $R / C$ are obtained by varying the values of $R$ and $C$ around the values of $R_{m}$ and $C_{m}$ predicted for the minimum area required for the time constant. These values are listed in table 1 and are plotted in figure 2. For this example, a value of $t$ equal to $1 \mu \mathrm{s}$ was chosen. The minimum $A_{t}$ on the curve agrees with the value of $A_{t_{m}}$ found by inserting these constants into equation (13). The $R / C$ ratio on the curve that corresponds to $A_{t_{m}}$ is $K_{r} / K_{c}$, as was predicted by equation (14). 
Table 1.-Determination of $A_{t_{m}}$

\begin{tabular}{|c|c|c|c|c|c|c|c|c|}
\hline$R, \mathrm{M} \Omega$ & $C, \mathrm{pF}$ & \multicolumn{2}{|c|}{$A_{r}, \mu \mathrm{m}^{2}\left(10^{-6} \mathrm{in}^{2}\right)$} & \multicolumn{2}{|c|}{$A_{c}, \mu \mathrm{m}^{2}\left(10^{-6} \mathrm{in}^{2}\right)$} & \multicolumn{2}{|c|}{$A_{t}, \mu \mathrm{m}^{2}\left(10^{-6} \mathrm{in}^{2}\right)$} & $R / C, \Omega / \mathrm{F}$ \\
\hline 0.05 & 20 & 1290 & $(2.00)$ & 51610 & $(80)$ & 52900 & $(82)$ & $0.25 \times 10^{15}$ \\
.1 & 10.0 & 2580 & $(4.0)$ & 25810 & $(40.0)$ & 28390 & $(44.0)$ & $1.0 \times 10^{16}$ \\
.2 & 5.0 & 5160 & $(8.0)$ & 12900 & $(20.0)$ & 18060 & $(28.0)$ & $4.0 \times 10^{16}$ \\
.25 & 4.0 & 6450 & $(10.0)$ & 10320 & $(16.0)$ & 16770 & $(26.0)$ & $6.25 \times 10^{16}$ \\
.316 & 3.16 & 7783 & $(12.64)$ & 7783 & $(12.64)$ & 16310 & $(25.28)$ & $1.0 \times 10^{17}$ \\
.4 & 2.5 & 10320 & $(16.0)$ & 6450 & $(10.0)$ & 16770 & $(26.0)$ & $1.6 \times 10^{17}$ \\
.5 & 2.0 & 12900 & $(20.0)$ & 5160 & $(8.0)$ & 18060 & $(28.0)$ & $2.5 \times 10^{17}$ \\
1.0 & 1.0 & 25810 & $(40.0)$ & 2580 & $(4.0)$ & 28390 & $(44.0)$ & $1.0 \times 10^{18}$ \\
2.0 & .5 & 51610 & $(80.0)$ & 1290 & $(2.0)$ & 52900 & $(82.0)$ & $4.0 \times 10^{18}$ \\
\hline
\end{tabular}

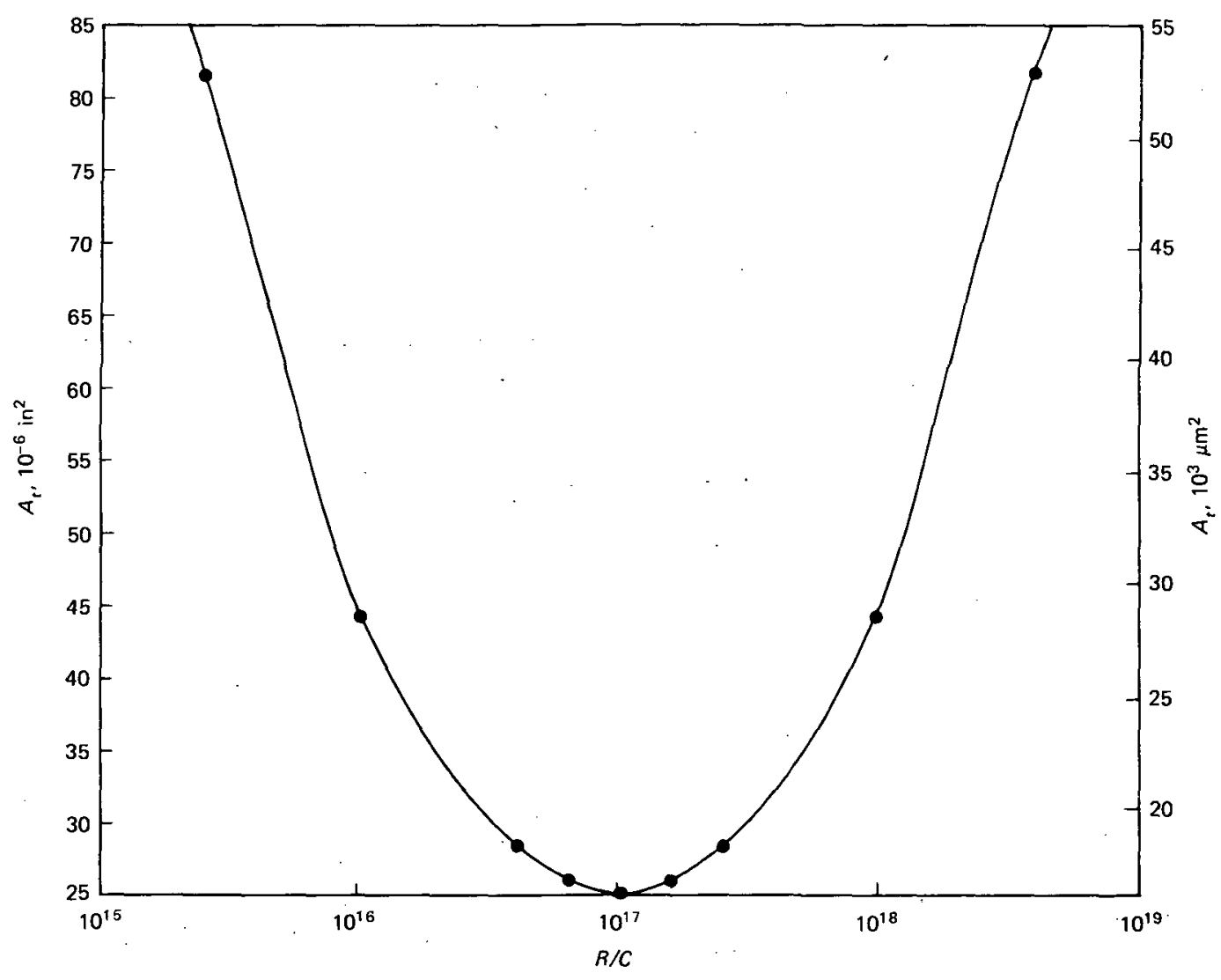

Figure 2. $-A_{t_{m}}$ as a function of $R / C$.

Goddard Space Flight Center

National Aeronautics and Space Administration

Greenbelt, Maryland, June 8, 1972

861-41-75-01-51 
"The aeronautical and space activities of the United States shall be conducted so as to contribute ... to the expansion of buman knowledge of phenomena in the atmosphere and space. The Administration shall provide for the widest practicable and appropriate dissemination of information concerning its activities. and the results thereof."

-National Aeronautics and Space ACt of 1958

\title{
NASA SCIENTIFIC AND TECHNICAL PUBLICATIONS
}

TECHNICAL REPORTS: Scientific and technical information considered important, complete, and a lasting contribution to existing knowledge.

TECHNICAL NOTES: Information less broad in scope but nevertheless of importance as a contribution to existing knowledge.

TECHNICAL MEMORANDUMS:

Information receiving limited distribution because of preliminary data, security classification, or other reasons. Also includes conference proceedings with either limited or unlimited distribution.

CONTRACTOR REPORTS: Scientific and technical information generated under a NASA contract or grant and considered an important contribution to existing knowledge.
TECHNICAL TRANSLATIONS: Information published in a foreign language considered to merit NASA distribution in English.

SPECIAL PUBLICATIONS: Information derived from or of value to NASA activities. Publications include final reports of major projects, monographs; data compilations, handbooks, sourcebooks, and special bibliographies.

\section{TECHNOLOGY UTILIZATION}

PUBLICATIONS: Information on technology used by NASA that may be of particular interest in commercial and other non-aerospace applications. Publications include Tech Briefs, Technology Utilization Reports and Technology Surveys.

Defails on the availability of these publications may be obtained from:

SCIENTIFIC AND TECHNICAL INFORMATION OFFICE

\author{
NATIONAL AERONAUTICS AND SPACE ADMINISTRATION \\ Washington, D.C. 20546
}

